Revista Monografias Ambientais - REMOA v. 15, n.1, jan-abr. 2016, p.209-219

Revista do Centro de Ciências Naturais e Exatas - UFSM, Santa Maria

e-ISSN 22361308 - DOI:10.5902/22361308

REMOA/UFSM

Monografias Ambientais

\title{
LEVANTAMENTO DA GERAÇÃO ANUAL DOS RESÍDUOS SÓLIDOS RECICLÁVEIS DO MUNICÍPIO DE CAÇADOR-SC.
}

\author{
Survey of annual generation of solid waste in the municipality of Caçador-SC.
}

\author{
Roger Francisco Ferreira de Campos, Tiago Borga
}

Universidade Alto Vale do Rio do Peixe - UNIARP, Universidade do Estado de Santa Catarina - UDESC e Instituto

Casa Viva - ICV

Resumo

\begin{abstract}
Um dos principais problemas ambientais é o impacto causado pela falta de gerenciamento dos resíduos sólidos urbanos, no qual pode ser reversível com a utilização das diretrizes do Plano Municipal de Gestão Integrado de Resíduos Sólidos. Objetivou-se com esse trabalho a caracterização física e composição gravimétrica dos resíduos recicláveis do município de Caçador-SC. O estudo foi realizado junto a Cooperativa Cidadania e Meio Ambiente e as empresas de reciclagem do município, no período de 01/01/2013 a 31/12/2013. Tendo um volume total amostrado de $2.602 .495,78 \mathrm{~kg} / \mathrm{ano}$, sendo um trabalho correspondente a toda área do município. Conforme levantado chegou $240.822,95 \mathrm{~kg}$ em janeiro, 233.634,37 kg em fevereiro, 219.155,3 kg em março, 219.155,3 kg em abril, 208.586,75 kg em maio, 187.469,51 kg em junho, $196.454,97 \mathrm{~kg}$ em julho, $196.074,00 \mathrm{~kg}$ em agosto, $189.068,27 \mathrm{~kg}$ em setembro, 198.913,48 $\mathrm{kg}$ em outubro, $216.272,66 \mathrm{~kg}$ em novembro e 234.449,65 kg em dezembro. Possuindo uma geração total de 324.554,02 $\mathrm{kg}$ de papel, 889.112,47 $\mathrm{kg}$ de papelão, 1.026.983,73 de plástico, 247.002,61 kg de vidro, 8.809,30 kg de eletrônico, 68.253,86 kg de alumínio, 38.122,78 $\mathrm{kg}$ de metal e 2.657,00 kg de ferro. Para a determinação da composição gravimétrica dos resíduos sólidos foi seguido a NBR 10007:04. A partir dessa foi possível levantar geração per capta do município de 36,77 kg/hab./ano, 3,06 kg/hab./mês e 0,101 kg/hab./dia, e a média amostral de cada um dos meses. Esses dados serão utilizados no Plano Municipal de Gestão Integrada de Resíduos Sólidos do município de Caçador, no qual vai impor as diretrizes referentes aos resíduos passiveis de reciclagem com os valores da pesquisa.
\end{abstract}

Palavras-chave: Reciclagem, Resíduos, Composição Gravimétrica e geração per capta.

\section{ABSTRACT}

One of the main environmental problems is the impact caused by the lack of solid waste management, in which may be reversible with the use of the guidelines of the Municipal Plan for Integrated Management of Solid Waste. The objective of this work the physical characterization and gravimetric composition of recyclable waste in the municipality of Caçador-SC. The study was carried out in the Cooperative Citizenship and Environment and the recycling companies in the municipality, in the period of service beginning on January 01/01/2013 will be 31.12.2013. Having a total volume sampled of 2,602,495.78 $\mathrm{kg} /$ year, it is a job for the entire area of the municipality. As raised came from a generation of 240,822.95 kg in January, 233,634.37 kg in February, 219,155.3 kg in March, 219,155.3 kg in April, 208,586.75 kg in May, $187,469.51 \mathrm{~kg}$ in June, 196,454.97 kg in July, 196,074.00 kg in August, 189,068.27 kg in September, 198,913.48 kg in October, 216,272.66 $\mathrm{kg}$ in November and $234,449.65 \mathrm{~kg}$ in December.Having a total generation of 324,554.02 $\mathrm{kg}$ of Paper, 889,112.47 $\mathrm{kg}$ of Cardboard, 1,026,983.73 Plastic, 247,002.61 kg of Glass, 8,809.30 kg of electronic, 68,253.86 kg of Aluminum, 38,122.78 kg of Metal and 2,657.00 kg of Iron. For the determination of gravimetric composition of these residues was followed by the NBR 10007:04.From this it was possible to raise generation per captures the municipality of $36.77 \mathrm{~kg} /$ inhab. /year, $3.06 \mathrm{~kg} / \mathrm{hab}$. /month and $0.101 \mathrm{~kg} / \mathrm{hab}$. /day, and the sample mean of each of the months. These data will be used in the Municipal Plan for the Integrated Management of Solid Waste in the municipality of Hunter, which will impose guidelines for waste was precluded recycling with the values of the survey.

Keywords: Waste. Recycling. Gravimetric Composition. Generation per capita. 


\section{INTRODUÇÃO}

Um dos principais problemas ambientais atualmente são os Resíduos Sólidos, sendo um sério desafio para a atualidade, com o crescimento populacional e o aumento do grau de urbanização não vem sendo acompanhado com a medida necessária para dar um destino adequado ao Resíduo Sólido Urbano (RSU) produzido (SANCHES et al., 2006).

O manejo inadequado de resíduos sólidos de qualquer origem gera desperdícios, constitui ameaça constante à saúde pública e agrava a degradação ambiental, comprometendo a qualidade de vida das populações, especialmente nos centros urbanos de médio e grande porte (SANCHES et al., 2006).

O município de Caçador é uma referência estadual devido a Guerra do Contestado e por ser a maior cidade do meio-oeste catarinense, tendo $984.285 \mathrm{~km}^{2}$. De acordo com o Instituto Brasileiro de Geografia e Estatística (IBGE), em 2000 a população de Caçador era de 63.322 habitantes, em 2010 o número cresceu para 70.762 habitantescom uma densidade demográfica de 0,69 hab./ha.

Segundo Campos (2015), Caçador-SC sofre com pontos irregulares de descarte de resíduos, onde cita que esses resíduos têm um alto potencial de reciclagem, sabendo que no ano de 2008 instituiu-se a Cooperativa Cidadania e Meio Ambiente- COOCIMA, a qual desenvolvendo a coleta seletiva para que resíduos sólidos urbanos recicláveis tenham a destinação correta no município. Além dessa existem empresas que obtém geração econômica a partir da reciclagem dos resíduos auxiliando no processo de melhoria paisagística da cidade.

Entre os ativos ambientais, os resíduos sólidos oferecem risco potencial ao meio ambiente. Essa questão vem sendo uma preocupação de órgãos da saúde, entidades ambientais e prefeituras, pois o crescimento acelerado dos municípios faz com que as áreas disponíveis para a destinação dos resíduos sólidos urbanos se tornem escassas (SISINNO; OLIVEIRA, 2000).

Segundo Teixeira e Zanin (1999), para haver uma melhor gestão e gerenciamento dos resíduos sólidos urbanos dos municípios brasileiros, primeiramente é preciso conhecer o que é gerado. Para isto, a caracterização gravimétrica do mesmo é de primordial importância. Além das características qualitativas é necessário conhecer a quantidade produzida por dia (ton/dia; $\mathrm{m}^{3} / \mathrm{dia}$ ) e a produção per capta (ton/hab./dia), para melhor gerenciamento dos resíduos sólidos (ZANTA; FERREIRA, 2003)

Segundo Campos (2015) o município de Caçador-SC recicla 10,538\% de Papel, 22,869\% de Papelão, 7,647\% de Tetra Pack, 3,048\% de Metal, 2,961\% de Alumínio, 9,885\% de Vidro, 11,169\% de Plástico Flexível, 13,150\% de Plástico Duro, 6,862\% de PET, 0,499\% de Isopor e 0,643\% de Eletrônico.

A Política Nacional de Resíduos Sólido (PNRS) instituído pela Lei 12.305 de 02 de agosto de 2010 impõem que é de obrigatoriedade os municípios possuírem o Plano Municipal de Gestão Integrada dos Resíduos Sólidos para que os mesmos possam dar diretrizes aos resíduos sólidos gerados (PNRS, 2012). Para ampliar o estudo gravimétrico realizado por Campos (2015), esse estudo visa buscar uma quantidade aproximada de quanto o município de Caçador-SC gera de resíduos recicláveis e a geração per capta. 
Assim, este trabalho tem como objetivo avaliar a quantidade de material que é reciclado no município de Caçador, no período de um ano (2013), pelo método de composição gravimétrica. Para essa determinação foi levantado o número de impressas que realizam a reciclagem e a quantidade de material reciclado pela única cooperativa do município, em seguida foi aplicado à técnica da NBR 10007:2004, após foi realizado a separação e a pesagem dos resíduos.

\section{MATERIAIS E MÉTODOS}

O estudo foi realizado no Município de Caçador, localizado nas coordenas geográficas 26²6'07.5" S e 5059'41.4" W, na região do meio oeste do estado de Santa Catarina, no Alto Vale do Rio do Peixe, a $400 \mathrm{~km}$ de Florianópolis.Compondo uma área $984,285 \mathrm{~km}^{2}$, possuindo uma população de 70,762 habitantes, segundo IBGE (2010). Sendo que 6.304 residem na área rural, representando 8,91\% e 64.431 na área urbana com 91,09\% em domicílios.

Os dados foram levantados a partir de empresas e uma cooperativa que realiza o processo de reciclagem no município de Caçador-SC. O estudo foi equivalente ao período de um ano (2013). Para realizar o estudo foi encaminhado um oficio pela Fundação Municipal do Meio Ambiente FUNDEMA solicitando o acesso às empresas recicladoras para realizar o levantamento gravimétrico aplicando à técnica da NBR 10007:2004 com a realização da separação e pesagem do resíduo.

Para realizar o levantamento na Cooperativa Cidadania e Meio Ambiente - COOCIMA foi adquirido à porcentagem apresentada no estudo de levantamento gravimétrico conforme (CAMPOS, 2013), confrontando com os valores apresentado pela empresa que realiza coleta seletiva e a partir disso obtendo o valor de quanto à cooperativa recicla ano.

Foram levantadas a geração de todas as classes de papel, papelão, plástico, vidro, eletrônicos, alumínio, metal e ferro.

\section{RESULTADOS E DISCUSSÃO}

Atualmente Caçador possui cinco empresas que realiza reciclagem e uma cooperativa, os resultados apresentados são de janeiro de 2013 a dezembro de 2013, assim avaliando um valor aproximado de quanto à cidade recicla anualmente no qual se obteve um valor de 2.602.495,78 $\mathrm{kg} / \mathrm{ano}$.

Para estabelecer a geração per capta do município de Caçador-SC, foi admitida a seguinte formula (1):

$$
K g / h a b=\frac{2.602 .495,78}{70.762}
$$

O estudo apresenta uma geração per capta de 36,77 kg/hab./ano, 3,06 kg/hab./mês e 0,101 $\mathrm{kg} / \mathrm{hab}$./dia. 
Segundo Brasil (2009) a geração per capita de resíduos sólidos no Brasil corresponde a 359 $\mathrm{kg} / \mathrm{hab}$./ano, sendo que a região sul gera $0,81 \mathrm{~kg} / \mathrm{hab}$./dia. Apesar do estudo se basear em resíduos sólidos orgânicos e recicláveis a geração per capita de Caçador comparado ao estudo seria de 12,5\% de resíduos recicláveis.

Segundo Abrelpe (2012) a geração per capita dos resíduos sólidos urbanos da região sul do Brasil em 2011 correspondeu a 0,887 kg/hab./dia e no ano de 2012 a geração aumentou para 0,905 $\mathrm{kg} / \mathrm{hab}$./dia correspondendo a um aumento de 2,0\% na geração de resíduos sólidos urbanos. Santa Catarina obteve uma geração per capita de 0,763 kg/hab./dia no ano de 2011, no ano de 2012 obteve uma geração per capita de 0,809kg/hab./dia obtendo um aumento na geração de 0,046kg/hab./dia.

Tabela 1. Levantamento gravimétrico e geração per capta Ano, Mês e Dia do município de Caçador/SC.

\begin{tabular}{c|c|c|c|c|c}
\hline MESES & $\begin{array}{c}\text { Resíduos/ } \\
\text { Total kg }\end{array}$ & Porcentagem & $\begin{array}{c}\text { per captal kg } \\
\text { Ano }\end{array}$ & $\begin{array}{c}\text { per captal kg } \\
\text { Mês }\end{array}$ & $\begin{array}{c}\text { per capta/ } \mathrm{kg} \\
\text { Dia }\end{array}$ \\
\hline Janeiro & $240.822,95$ & $9 \%$ & - & 3,94 & 0,127 \\
\hline Fevereiro & $233.634,37$ & $9 \%$ & - & 3,30 & 0,118 \\
\hline Março & $219.155,30$ & $8 \%$ & - & 3,09 & 0,103 \\
\hline Abril & $281.597,01$ & $11 \%$ & - & 3,98 & 0,132 \\
\hline Maio & $208.586,75$ & $8 \%$ & - & 2,95 & 0,100 \\
\hline Junho & $187.469,51$ & $7 \%$ & - & 2,65 & 0,101 \\
\hline Julho & $196.454,97$ & $8 \%$ & - & 2,77 & 0,090 \\
\hline Agosto & $196.074,00$ & $8 \%$ & - & 2,77 & 0,090 \\
\hline Setembro & $189.068,27$ & $7 \%$ & - & 2.67 & 0,089 \\
\hline Outubro & $198.913,48$ & $8 \%$ & - & 2,81 & 0,090 \\
\hline Novembro & $216.272,66$ & $8 \%$ & - & 3,06 & 0,102 \\
\hline Dezembro & $234.449,65$ & $9 \%$ & - & 3,31 & 0,106 \\
\hline TOTAL/ & $\mathbf{2 . 6 0 2 . 4 9 5 , 7 8}$ & $\mathbf{1 0 0} \%$ & $\mathbf{3 6 , 7 7}$ & $\mathbf{3}, 06$ & $\mathbf{0 , 1 0 1}$ \\
\hline MÉDIA & & & & & \\
\hline
\end{tabular}

Os meses de janeiro e abril foram os que mais possuem geração per capta e o mês de setembro foi o que menor possuiu geração per capta. Segundo Campos (2015) o valor reciclado e produzido por cada habitante/dia é de 1,39 kg/mês a partir de um estudo gravimétrico realizado no mês de agosto na cooperativa do município. Assim, com esse estudo aprofundado contribuindo para novas diretrizes do manejo dos resíduos. 
Tabela 2. Geração de resíduos sólidos recicláveis do município de Caçador-SC.

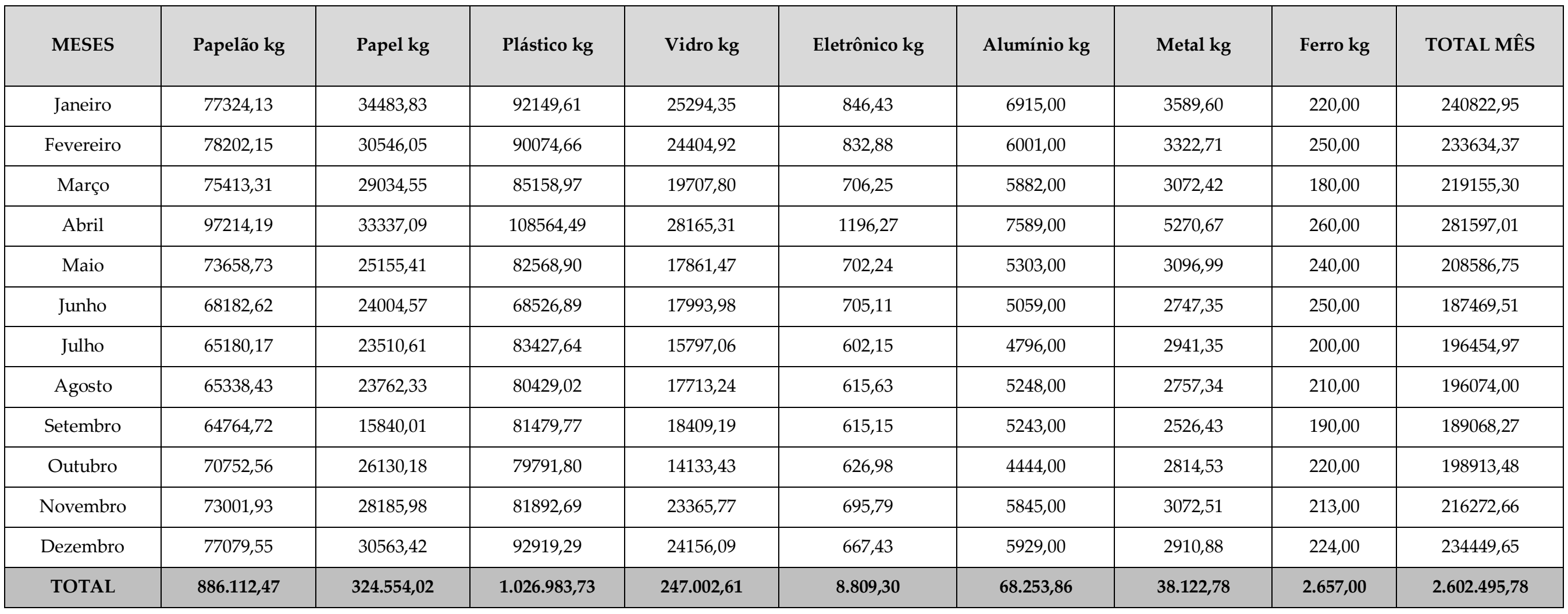


Gráfico 1. Porcentagem total de resíduos recicláveis geradosnos meses de 2013;

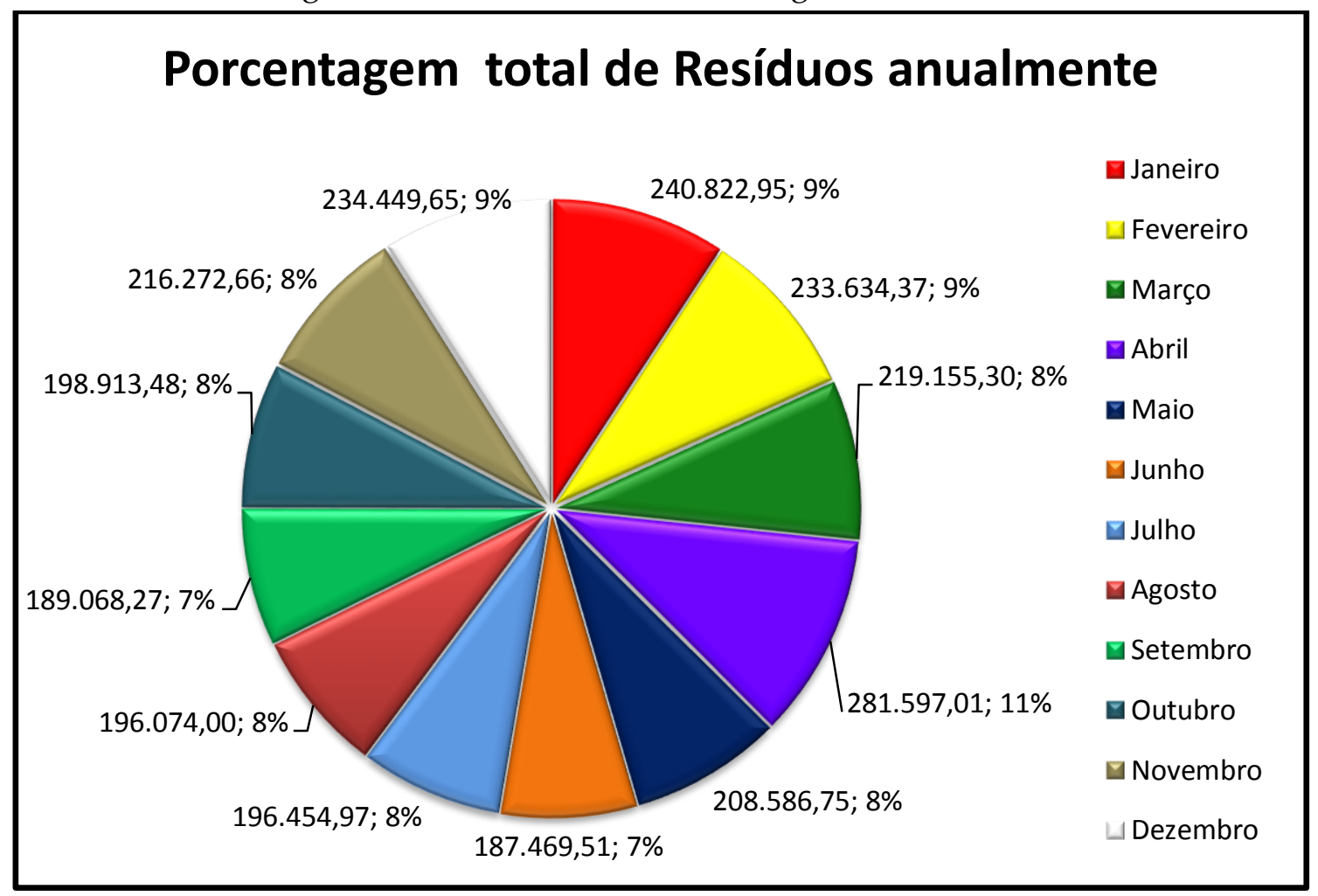

Conforme estudo o ano de 2013 obteve uma geração de $2.602 .495,78 \mathrm{~kg} /$ ano no total dos meses, sendo que, obeteve um gereação de 240.822,95 kg em janeiro, 233.634,37 kg em fevereiro, 219.155,3 $\mathrm{kg}$ em março, 219.155,3 kg em abril, 208.586,75 kg em maio, 187.469,51 kg em junho, 196.454,97 kg em julho, 196.074,00 kg em agosto, 189.068,27 kg em setembro, 198.913,48 kg em outubro, $216.272,66 \mathrm{~kg}$ em novembro e $234.449,65 \mathrm{~kg}$ em dezembro.

O estudo apresenta uma porcentagem de 9\% em janeiro, $9 \%$ em fevereiro, $8 \%$ em março, $11 \%$ em abril, $8 \%$ em maio, $7 \%$ em junho, $8 \%$ em julho, $8 \%$ em agosto, $7 \%$ em setembro, $8 \%$ em outubro, $8 \%$ em novembro e $9 \%$ em dezembro.

O mês de abril foi o que mais efetuo reciclagem com $219.155,3 \mathrm{~kg} /$ mês e o que menos efetuo foi o mês de julho com apenas 196.454,97 kg/mês.

Segundo Campos e Lima (2015), mostra que nos mês com datas festivas como natal, carnaval, virada de ano e dias das mães o verejo do município de Caçador realiza mais compras de produtos, assim tendo uma maior gerações de resíduos reciclaveis, mostrando uma geração de $1.673,41 \mathrm{Kg} / \mathrm{mês}$ em janeiro, 1.011,28 kg/mês em fevereiro, 1.076,44 kg/mês em março, 1.167,67 kg/mês em abril, 1.110,00 kg/mês maio, 937,69 em junho, 1.074,70 kg/mês em julho, 1094,27 kg/mês em agosto, 936,53 kg/mês em setembro, $1.402,50 \mathrm{~kg} / \mathrm{mêsem}$ outubro, $1.442,14 \mathrm{~kg} / \mathrm{mês}$ em novembro e $1.442,61 \mathrm{~kg} / \mathrm{mês}$ em Dezembro em um supermercado do município. 
Gráfico 2. Porcentagem dos resíduos recicláveis no ano estudado;

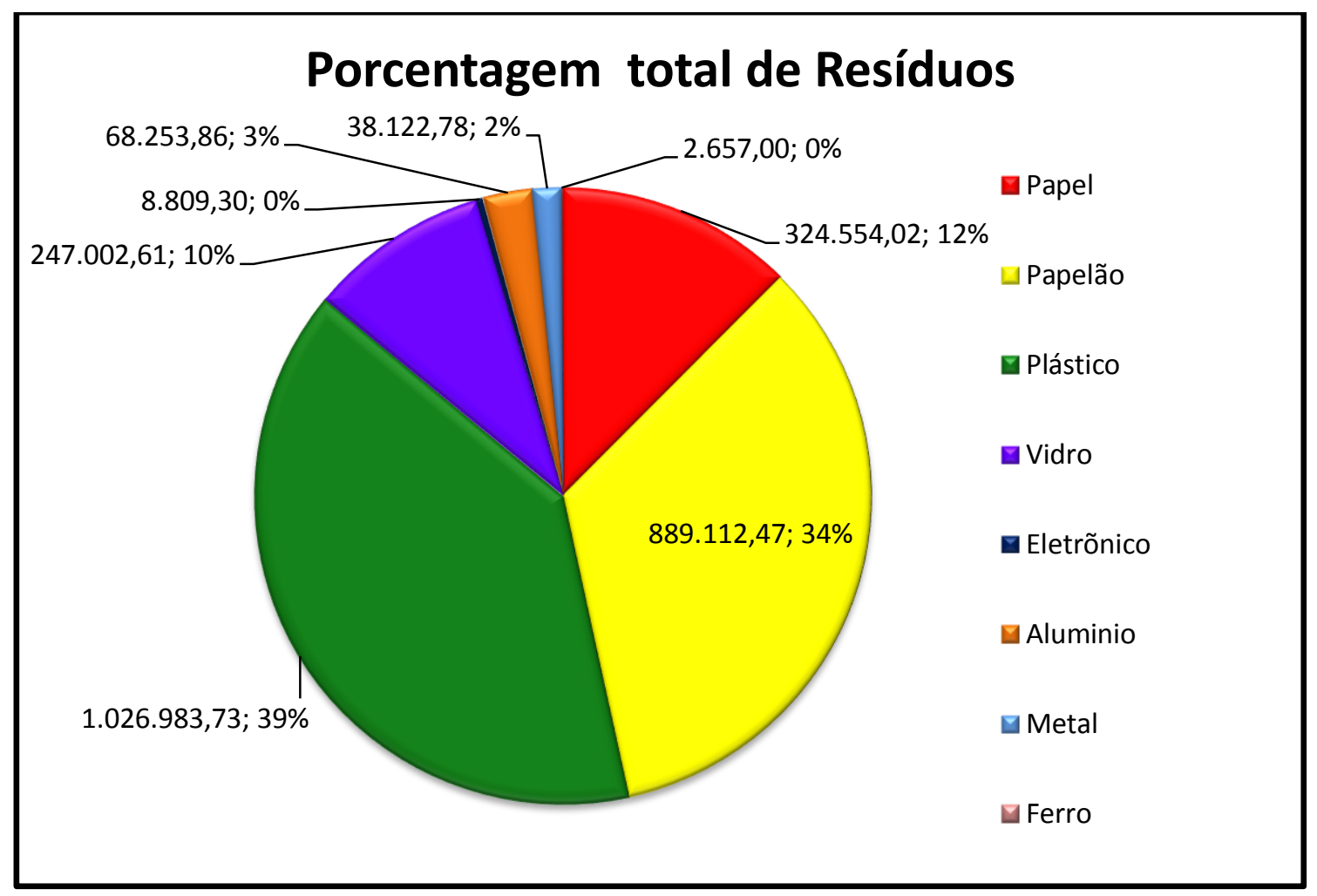

$\mathrm{O}$ ano estudado apresenta uma geração de $324.554,02 \mathrm{~kg}$ de papel, $889.112,47 \mathrm{~kg}$ de papelão, $1.026 .983,73 \mathrm{~kg}$ de plástico, 247.002,61 kg de vidro, 8.809,30 kg de eletrônico, 68.253,86 kg de alumínio, $38.122,78 \mathrm{~kg}$ de metal e $2.657,00 \mathrm{~kg}$ de ferro. O plastico possui a maior geração de resíduos, correspondendo a $39 \%$, logo atrás vem o papelão com $34 \%$ e o papel com $12 \%$.

A geração dos principais materias no total dos residuos sólidos urbanos no Brasil, em 2011 corresponde à 13,1\% ou 7.409.603 t/ano de (papel, papelão e tetrapak), 13,5\% ou 7.635.851 t/ano de (plástico) de um total de 56.561.856 t/ano (ABRELPE, 2011).

Segundo Campos e Lima (2014), em seu levantamento gravimétrico de um supermercado localizado no municipio de Caçador-SC, apresenta uma geração de 9083,56 kg/ano de papelão, $736,51 \mathrm{~kg} /$ ano de papel e 3.192,10 kg/ano de plástico. Seu processo de gestão dos resíduos no qual tem como destinação uma das empresas privadas de reciclagem do município.

Segundo Machado e Guadagnin (2008), o município de Criciúma-SC (192.308 habitantes) apresentou uma geração de $67 \%$ de papel, 22,83 de plástico, $9 \%$ de vidro e $0,69 \%$ de metal no período de um ano, correspondente a área urbana. Comparando com o município de Criciúma-SC, Caçador é mais seletivo no seu processo de reciclagem, por isso apresenta um valor inferior com plástico, papel e metal. Porém com vidro apresenta uma porcentagem maior de $1 \%$.

Segundo SNIS (2015) no diagnóstico do manejo de resíduos sólidos urbanos em 2013 os estados brasileiros possuem um valor máximo na geração per capta de 2,08 kg/hab./dia e um valor mínimo na geração per capta de $0,50 \mathrm{~kg} / \mathrm{hab}$./dia de resíduos sólidos domiciliares e públicos. Nesse estudo o 
estado de Santa Catarina possui uma geração média per capta de 0,81 kg/hab./dia, no mesmo estudo cita que cidades de $30.001 \mathrm{mil}$ a 100.000 mil habitantes possuem uma geração de 0,90 $\mathrm{kg} / \mathrm{hab}$./dia de resíduos sólidos domiciliares e públicos.

O diagnóstico realizado pela SNIS apresenta uma geração de 599,2 ton/munic./ano e uma geração de 29,1 kg/hab./ano de resíduos sólidos coletados via coleta seletiva (SNIS, 2015). Comparado com o estudo do SNIS Caçador obteve uma geração de $2.602,5 \mathrm{~kg} /$ munic./ano e uma geração de 36,77 kg/hab./ano.

Essa diferença de valor pode ser atribuída ao diagnostico realizado pelo SNIS ser baseado somente na coleta seletiva, já o estudo realizado em Caçador se baseou em mais pontos de dados com empresas de reciclagem não vinculada a coleta seletiva.

Baseado no diagnóstico do SNIS o estudo de Caçador corresponderia a uma geração de 12,5\% de resíduos recicláveis e $87,5 \%$ de resíduos orgânicos, baseado na geração de $0,81 \mathrm{~kg} / \mathrm{hab}$./dia de Santa Catarina e 0,101 kg/hab./dia de Caçador.

Segundo IPEA (2012) são coletadas 183,5 ton/dia de resíduos sólidos no Brasil, em 90\% do total de domicílios, $98 \%$ representa as moradias urbanas, 33\% as rurais, compõem 51,4\% de resíduos orgânicos e 31,9\% de resíduo reciclável.Em 2013 a geração total de resíduos sólidos foi de 76.387.200 ton/ano, representando 4,1\% mais que o ano de 2012 (ABRELPE, 2013).

Segundo COMCAP (2009) a caracterização do material da coleta seletiva do município de Florianópolis-SC compõe uma geração de $23 \%$ de papelão, $26 \%$ de papel misto, $9 \%$ de papel branco, $3 \%$ de plástico mole, $9 \%$ de plástico duro, $4 \%$ de ferro, $0 \%$ de alumínio, $11 \%$ de vidro e $15 \%$ de rejeito.

Segundo Prandini (2012), através de um estudo gravimétrico na Cooperativa de Caçador-SC, se obeteve $36,36 \%$ de papel, $25,70 \%$ de plástico, 11,84\% de metal e vidro com 15,96\%, de um total de $459,13 \mathrm{~kg} / \mathrm{mês}$ amostrado em setembro. Em 2013 em um estudo mais aprofundado pode se obter um geração de papel com 10,538\%, papelão com 22,869\%, Tetra Pack com 7,647\%, metal com $3,048 \%$, alumínio com 2,961\%, vidro com $9,885 \%$, plástico flexível com 11,169\%, plástico duro com 13,150\%, PET com 6,862\%, orgânico com 2,942\%, isopor com 0,499\%, eletrônico com 0,643\%, lâmpadas com $0,566 \%$, pilhas com $0,420 \%$, rejeito com 3,242\% e sanitário com 3,559\% de um total amostrado de 883,037 kg/mês (CAMPOS, 2015).

No presente estudo o município do estudo possui uma geração de $12 \%$ de papel, $34 \%$ de papelão, 39\% de plástico, $10 \%$ de vidro, $0,34 \%$ de eletronico, $3 \%$ de aluminio, $2 \%$ de metal e $0,102 \%$ de ferro. Comparado à caracterização do município de Caçador com a de Florianópolis, o município do estudo possui ama porcentagem aproximada de vidro os demais resíduos possuem porcentagens diferentes.

Segundo Gonçalves e Dias (2007), no município de Uberlândia-MG estima-se que sejam gerados 605,77 t/mês, que possui 585.262 habitantes, tendo uma geração per capita mensal de 1,04 $\mathrm{kg} / \mathrm{hab} . / \mathrm{mês}$. Em comparação ao município de Minas Gerais a geração per capita de Caçador é maior, onde possui 3,06 kg/hab./mês.

Almeida (2012) em seu estudo de Caracterização gravimétrica do material destinado ao aterro de Caçador-SC cita que a geração per capta de resíduos orgânicos do município é de 0.164 kg/hab./mês. Porém no ano de 2009 a geração per capta era de 0.212 kg/hab./mês (KLEINE, 2009), 
no qual se pode observar uma diminuição da geração per capta de resíduos de 0,048 kg/mês. Esse valor pode ser atribuído à implantação da coleta seletiva em Caçador. No qual o município possui uma geração per capta atual de 3,06 kg/hab./mês, além de diminuir os resíduos destinados ao aterro esse processo de reciclagem contribuiu para a limpeza do município.

Campos (2015) e Almeida (2012) citam que 23,95\% do material que está sendo destinado ao aterro é passível de reciclagem correspondendo a 2.737,23 toneladas de material com destinação imprópria.

Segundo Campos (2015) os resíduos amostrados em seu levantamento gravimétrico, são destinados a COOCIMA 10,73\% de materiais não passiveis de reciclagem como orgânicos, rejeito e sanitários, correspondendo a 132,73 toneladas. As questões das diretrizes dos resíduos como orgânico e reciclável, mostram que o município ainda precisa melhor seu processo de reciclagem e destinação dos resíduos. Porém necessita de um melhoramento na gestão pública dos resíduos sólidos para que o município de Caçador se torne uma cidade modelo no processo de destinação correta de resíduos como reciclagem.

A partir do ano de 2012, Caçador-SC está passando por mudança referente à gestão dos resíduos, no qual está sendo um assunto altamente tratadas entre as entidades públicas e privadas. Com a implantação e competência do Plano Municipal de Gestão Integrada dos Resíduos Sólidos, busca-se um caminho eficiente para que os resíduos antes não reciclados possam ter uma destinação correta com reciclagem e compostagem, ou a implantação de triagem no aterro sanitário do município.

\section{CONCLUSÃO}

Através do estudo de caracterização gravimétrica e dos resíduos recicláveis do município de Caçador-SC, foi possível identificar uma geração per capita de 36,77 kg/hab./ano, 3,06 kg/hab./mês e 0,101 kg/hab./dia.

Os dados obtidos permitem concluir que os resíduos do mês produzidos são: Janiero de 240.822,95 kg, 233.634,37 kg em Fevereiro, 219.155,3 kg em Março, 219.155,3 kg em Abril, 208.586,75 kg em Maio, 187.469,51 kg em Junho, 196.454,97 kg em Julho, 196.074,00 kg em Agosto, $189.068,27 \mathrm{~kg}$ em Setembro, 198.913,48 kg em Outubro, 216.272,66 kg em Novembro e 234.449,65 kg em Dezembro, a partir do valor amostrado $2.602 .495,78 \mathrm{~kg} / \mathrm{ano}$.

O ano em estudo apresentou uma geração de 324.554,02 kg/ano de Papel, 889.112,47 kg/ano de Papelão, 1.026.983,73 kg/ano de Plástico, 247.002,61 kg/ano de Vidro, 8.809,30 kg/ano de eletrônico, $68.253,86$ kg/ano de Alumínio, 38.122,78 kg/ano de Metal e 2.657,00 kg/ano de Ferro.

Esse estudo será de utilidade para o Plano Municipal de Gestão Integrada dos Resíduos Sólidos, no qual contribuirá para os dados e as diretrizes referente aos resíduos sólidos reciclaveis. Sendo assim, este trabalho oferece informações sobre o potencial de resíduos recicláveis e a quantidade de resíduo gerado em todo o município de Caçador-SC, além da taxa de geração per capta que podem servir como ferramentas para a implantação ou melhorias nas políticas públicas e ambientais relacionadas ao tema. 


\section{AGRADECIMENTOS}

Agradeço as empresas recicladoras pelo suporte para realização do estudo e aos funcionários da Fundação Municipal do Meio Ambiente - FUNDEMA Gustavo Kucher Furlin e Luis Gustavo Pavelsck, pela dedicação e ensinamento ao presente trabalho.

\section{REFERENCIAS BIBLIOGRAFICAS}

ALMEIDA, R. G.. Estudo de geração de resíduos sólidos domiciliar urbanos no município de Caçador-SC, Á partir caracterização física e composição Gravimétrica. Revista Engenharias e Inovação Tecnológica- IGNIS, Pag. 71-92.

Abrelpe (2012). Panorama dos Resíduos Sólidos no Brasil 2011. Disponível em: http://www.abrelpe.org.br/panorama_apresentacao.cfm. Acesso em: 18 de maio de 2015.

Abrelpe (2013). Panorama dos Resíduos Sólidos no Brasil 2012.Disponível em: http://www.abrelpe.org.br/panorama_apresentacao.cfm. Acesso em: 18 de maio de 2015.

BRASIL. Ministério da Fazenda.Economia brasileira em perspectiva. Disponível em: http://www. fazenda.gov.br/portugues/docs/perspectiva-economia-brasileira/ edicoes/Economia-Brasileira-Em-Perpectiva-JunJul10.pdf. Acesso em: 8 de outubro de 2014.

CALDERONI, D. Os bilhões perdidos no lixo. São Paulo: Humanitas, 1998.

Companhia Melhoramentos da Capital - COMCAP.Gestão dos Resíduos Sólidos Urbanos do Município de Florianópolis, Florianópolis, Pag.148-149, 2000.

CAMPOS, R. F. F.; LIMA, C..Sustentabilidade através de remanejo de resíduos com prática de gestão ambiental implantado no supermercado cereal. Revista Engenharias e Inovação Tecnológica- IGNIS, n.1, v.3, pag. 25-44, 2015.

CAMPOS, R. F. F. Fundema: Perimetral Norte SC-350 esta como pontos irregulares de descarte de resíduos.Disponível em: http://fundemacacador.blogspot.com.br/. Acesso em: 29 de julho de 2013.

CAMPOS, R. F. F. Meio Ambiente: Estudo da Fundema relata o que os Caçadorenses reciclam. Disponível em: http://www.cacador.sc.gov.br/portalhome/index.php/noticias/fundema/2441-meio-ambiente. Acesso em: 29 de julho de 2013.

FADINI, P.S.; FADINI, A.A.B. Lixo: desafios e compromissos. Cadernos temáticos de Química Nova na Escola. São Paulo: Sociedade Brasileira de Química. no 1. maio de 2001. p. 9-18.

GONÇALVES, B.B.; DIAS, J.F..Resíduos Domiciliares Recicláveis: Prospecção para cidades de médio porte. OBSERVATORIUM: Revista Eletrônica de Geografia, v.1, n.1, p.84-104; 2007. 
Instituto Brasileiro de Geografia e Estatística. Estatístico Populacional censo 2010 (Online). Disponível em: http://www.ibge.gov.br/home/estatistica/populacao/censo2010/tabelas_pdf/total_populacao_santa_catarina.pdf Acesso em 29 de Março de 2012.

Instituto de Pesquisa Econômica Aplicada - IPEA. Brasil coleta 183,5 mil toneladas de resíduos sólidos/dia. (Online). Disponível em: http://www.ipea.gov.br/portal/index.php?option=com_content\&view=article\&id=13932. Acesso em 29 de Março de 2015.

KLEINE, A.. Composição gravimétrica dos resíduos sólidos urbanos domiciliares do município de Caçador SC. Trabalho de conclusão de curso apresentado como exigência para a obtenção do título de Engenheiro Ambiental. Universidade do Contestado - UNC, Caçador, 2009.

PADRINE, Liziane. Caracterização Gravimétrica do Material reciclável destinado à Coocima pelo programa de coletada seletiva do Município de Caçador- SC. Trabalho de conclusão de curso apresentado como exigência para Obtenção do titulo de Bióloga. Universidade Alto Vale do Rio do Peixe- UNIARP, Caçador-SC, 2012.

PNUD. 2001. Programa das Nações Unidas para o Desenvolvimento. Disponivel em: www.pnud.org.br. Acesso em:29 de julho de 2013.

SANCHES, S.N.; SILVA C.H.T.P.; VASPA, I.C.G.; VIEIRA, E.M..A importância da Compostagem para a educação Ambiental nas Escolas. Química Nova na Escola. São Paulo: Sociedade Brasileira de Química. № 23. Maio de 2006. P. 1013.

SISINNO, C. L. S.; OLIVEIRA, R. M., 2000, “Impacto Ambiental dos Grandes Depósitos de Resíduos Urbanos e Industriais". In: Sisinno, C. L. S., Oliveira, R. M. (org.), Resíduos Sólidos, Ambiente e Saúde: uma Visão Multidisciplinar, $1^{\underline{a}}$ ed, capítulo 1, Rio de Janeiro, Editora Fiocruz.

Sistema Nacional de Informação Sobre Saneamento - SNIS. Diagnóstico do Manejo de Resíduos Sólidos Urbanos 2013, Ministérios das cidades, Brasília, 2015.

GUADAGNIN, M.R.; MACHADO, M.G..Análise da composição gravimétrica dos resíduos sólidos urbanos recicláveis da Cooperativa Trabalhadores de Materiais Recicláveis em Criciúma - CTMAR, do estado de Santa Catarina - Brasil. In: Simpósio Internacional de Qualidade Ambiental. 6., 2008. Porto Alegre. Anais... Porto Alegre: ABES, 2008.

TEIXEIRA, Bernardo A. N.; ZANIN, Maria. Metodologia técnica de minimização, reciclagem e reutilização de resíduos Sólidos Urbanos. Rio de Janeiro; Associação Brasileira de Engenharia Sanitária e Ambiental, 1999.

ZANTA, V. M.; FERREIRA, C. F. A. Gerenciamento integrado de resíduos sólidos urbanos. In: Resíduos sólidos urbanos: aterro sustentável para municípios de pequeno porte. PROSAB. Rima Artes e Texto - São Carlos, SP, p.1-18, 2003. 